\title{
Study of the Plasmon Energy Transfer Processes in Dye Sensitized Solar Cells
}

\author{
Tzu-ming Chien, ${ }^{1}$ Prathamesh Pavaskar, ${ }^{2}$ Wei Hsuan Hung, ${ }^{1}$ Stephen Cronin, \\ Sheing-Hui Chiu, ${ }^{1}$ and Sz-Nian Lai ${ }^{1}$ \\ ${ }^{1}$ Department of Materials Science and Engineering, Feng Chia University, Taichung 407, Taiwan \\ ${ }^{2}$ Department of Electrical Engineering, University of Southern California, Los Angeles, CA 90089, USA
}

Correspondence should be addressed to Wei Hsuan Hung; whung@fcu.edu.tw

Received 20 November 2014; Accepted 28 January 2015

Academic Editor: Bin Zhang

Copyright (C) 2015 Tzu-ming Chien et al. This is an open access article distributed under the Creative Commons Attribution License, which permits unrestricted use, distribution, and reproduction in any medium, provided the original work is properly cited.

\begin{abstract}
We report plasmon enhanced absorption in dye sensitized solar cells (DSSC) over a broad wavelength range. 45\% enhancement in the power conversion efficiency is observed with the inclusion of plasmonic gold nanoparticles (NPs). Photocurrent spectra show enhancement over the entire dye absorption range from $450 \mathrm{~nm}$ to $700 \mathrm{~nm}$, as well as in the near infrared (NIR) region above $700 \mathrm{~nm}$ due to the strong plasmon-induced electric fields produced by the gold NPs. The plasmon-induced electric field distribution of the island-like gold film is also investigated using finite-difference-time-domain (FDTD) calculations. Furthermore, photoluminescence spectra are performed in order to rule out the mechanism of plasmon energy transfer through Forster resonance energy transfer.
\end{abstract}

\section{Introduction}

Dye-sensitized solar cells (DSSCs) have gained much attention because of their promising power conversion efficiency and low fabrication cost. However, after the initial efficiency of $11 \%$ was reported in the mid-1990s [1,2], further improvement in cell performance has been slow, and the efficiency has remained considerably lower than theoretical maximum values $[3,4]$. Solar energy conversion consists of four basic processes: light absorption, exciton separation, carrier transportation, and collection. Several studies have investigated these four steps to improve cell performance, employing approaches such as increased molecular adsorption [5], broad spectrum absorption [6], and multiple exciton generation by a single photon $[7,8]$. As an alternative to modifying the absorbing dye molecule, plasmonic metal nanoparticles, which have strong surface plasmon resonance, can be integrated to improve light harvesting. In surface plasmon resonance, the collective oscillation of free electrons confined at the surface of metals can be induced when the frequency of incident light matches the plasmon frequency of irradiated metals [9-11]. These collective charge oscillations result in substantially enhanced electric fields near the surface of NPs, which can facilitate both light absorption and charge separation [12].

Plasmonic enhancement has been used in inorganic and organic thin-film solar cells [13-16] to increase the effective light absorption of host materials. Several methods have been developed for integrating plasmonic NPs into solar cells. For example, plasmonic nanostructures have been patterned on indium tin oxide (ITO) by applying electron beam lithography, which provides high controllability of nanostructures in shape, size, and separation [17], and nanoparticles have been blended within organic bulk heterojunction solar cells during active layer material synthesis [18, 19]. However, electron beam lithography is still not considered practical for large-scale fabrication, and the blending method poses problems of solubility and nonuniform distribution. Therefore, researchers are still searching for a simple and effective approach to incorporating plasmonic nanostructures into solar cells. 


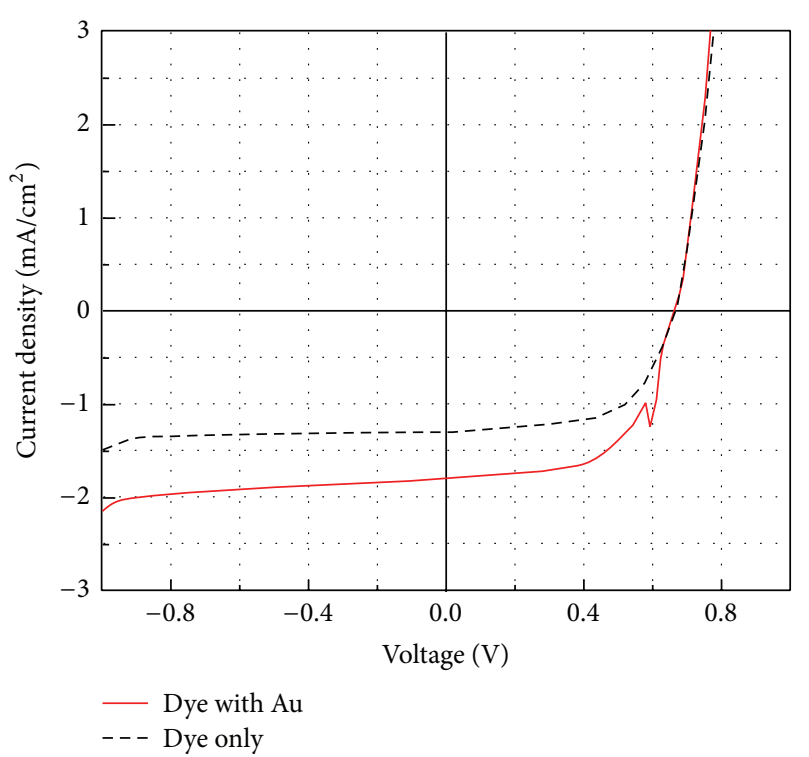

(a)

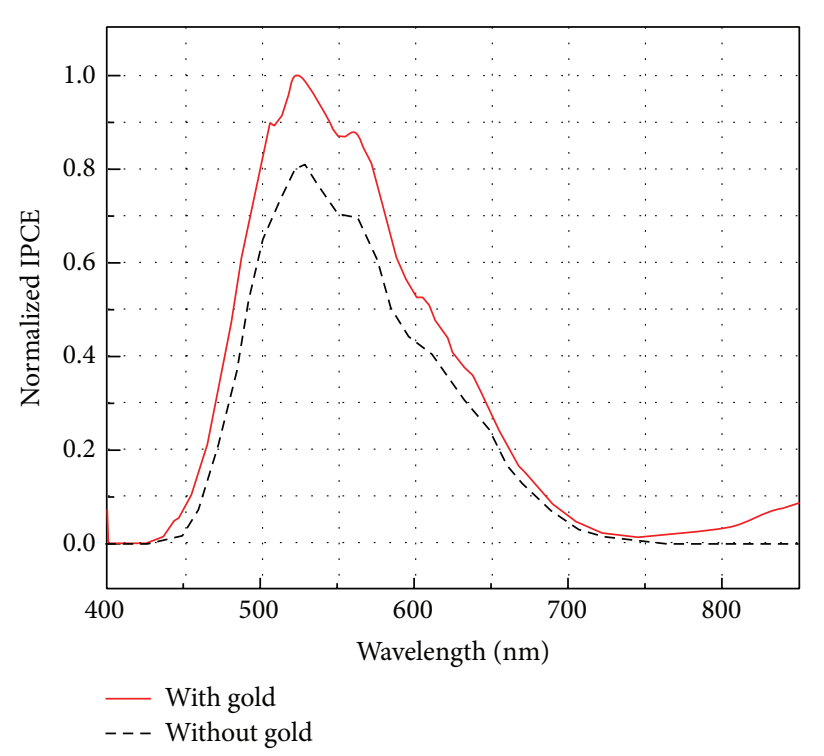

(b)

FIGURE 1: (a) $J-V$ characteristics of dye sensitized solar cells and (b) normalized incident photon-to-current conversion efficiency spectra with and without island-like gold nanostructures.

This paper proposes a simple and rapid method for fabricating plasmonic DSSCs. In this study, plasmonic NPs were produced using electron beam evaporation of a $5 \mathrm{~nm}$ gold $(\mathrm{Au})$ film on the surface of a dye-loaded $\mathrm{TiO}_{2}$ electrode. Because $5 \mathrm{~nm}$ is not a sufficient thickness for forming a continuous $\mathrm{Au}$ film, the film forms island-like nanostructures with few-nanometer separation. Strong electric fields within nanogaps between the island structures are referred to as hot spots. In addition to the $J-V$ characterization of DSSCs, the spectral response of the photocurrent is a measure for determining the enhanced region of absorption. Furthermore, FDTD simulations were conducted to investigate the distribution of plasmon-enhanced electric fields in the island-like nanostructures. Finally, the plasmonic energy transfer mechanism was examined using photoluminescence spectroscopy.

In this study, anodic $\mathrm{TiO}_{2}$ (ATO) was prepared using electrochemically oxidizing titanium foils in an ethylene glycol electrolyte containing $0.25 \mathrm{wt} \% \quad \mathrm{NH}_{4} \mathrm{~F}$ and $2 \mathrm{wt} \%$ $\mathrm{H}_{2} \mathrm{O}$ with an anodization potential of $30 \mathrm{~V}$ applied for $1 \mathrm{~h}$ $[20,21]$. Crystalline $\mathrm{TiO}_{2}$ can be achieved by performing an annealing treatment at $450^{\circ} \mathrm{C}$ for $5 \mathrm{~h}$ after anodization. Raman spectra were recorded after the annealing process and revealed the formation of anatase crystalline phase $\mathrm{TiO}_{2}$. Ruthenium-based dye (N719) (Sigma-Aldrich, Inc.) was used as a sensitizer in the solar device. The dye-loading process was completed by soaking the ATO anode in the N719 dye solution for $24 \mathrm{~h}$ and then rinsing it with isopropyl alcohol to remove the unattached dye on the surface of the ATO. A $5 \mathrm{~nm}$ plasmonic Au layer was deposited on the annealed $\mathrm{TiO}_{2}$ after the dye-loading process by using electron-beam evaporation at a rate of $1 \AA / \mathrm{s}$. The counter electrode consisted of ITO with an additional $1 \mathrm{~nm}$ layer of platinum $(\mathrm{Pt})$ on the surface, which accelerated the charge transfer process in the reduction of triiodide $\left(\mathrm{I}_{3}{ }^{-}\right)$[22]. Finally, the dye-loaded $\mathrm{TiO}_{2}$ electrode and Pt-coated ITO counter electrode were assembled into a sandwich-type cell by using a hot-melting seal foil at a thickness of $100 \mu \mathrm{m}$ purchased from Solarnix, Inc.

\section{Results and Discussion}

The $J-V$ characteristics of dye-sensitized cells with and without the incorporation of the plasmonic Au layer were measured using an AM 1.5 solar simulator equipped with a $450 \mathrm{~W}$ xenon lamp with a power output of $100 \mathrm{~mW} / \mathrm{cm}^{2}$ calibrated according to a reference silicon photodiode. Figure 1(a) shows a comparison of the photovoltaic measurement with and without island-like plasmonic nanostructures subjected to irradiation. The plasmon-enhanced cell exhibited an approximately $45 \%$ power conversion enhancement in the photocurrent $\left(1.81 \mathrm{~mA} / \mathrm{cm}^{2}\right)$ relative to that of the control cell $\left(1.25 \mathrm{~mA} / \mathrm{cm}^{2}\right)$ with a similar value of the open circuit voltage $\left(V_{\text {oc }}\right)$ and fill factor $(\mathrm{FF})$, as shown in Table 1.

Photocurrent spectra were measured with and without the $5 \mathrm{~nm}$ Au layer and plotted as a function of wavelength, as shown in Figure 1(b). The plasmon-enhanced cell exhibited an enhancement in photocurrent over the entire dye absorption range from 450 to $700 \mathrm{~nm}$ as well as the near-infrared tail above $700 \mathrm{~nm}$, which was due to additional charges from the $\mathrm{TiO}_{2}$ and was verified according to the absorption spectrum of the $\mathrm{TiO}_{2}$. This broad-band enhancement of the photocurrent in derived from the strong plasmon-induced electric fields and light scattering around the metal nanostructures, which resulted in widely enhanced light absorption in the actively absorbing host materials. Although the enhancement factors (EFs) were large, the overall efficiency of the devices 
TABLE 1: Summary characteristics of dye sensitized solar cell with and without plasmonic gold nanoparticles.

\begin{tabular}{lccccc}
\hline & $J_{\text {sc }}\left(\mathrm{mA} / \mathrm{cm}^{2}\right)$ & $V_{\text {oc }}(\mathrm{V})$ & FF & Efficiency $(\%)$ & Enhancement $(\%)$ \\
\hline w/o Au & 1.28 & 0.67 & 0.61 & 0.52 & $45 \%$ \\
w/ $\mathrm{Au}$ & 1.81 & 0.66 & 0.62 & 0.74 & \\
\hline
\end{tabular}

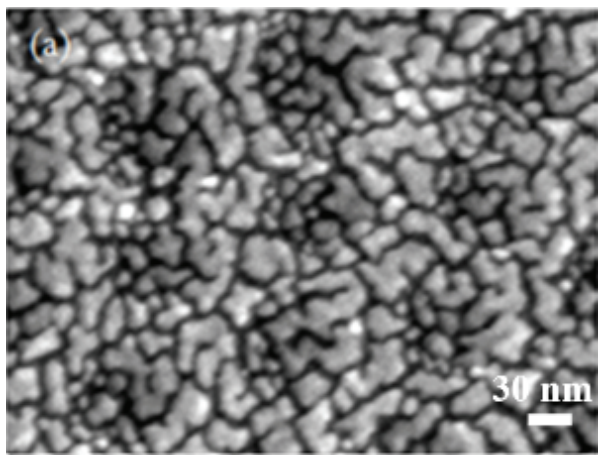

(a)

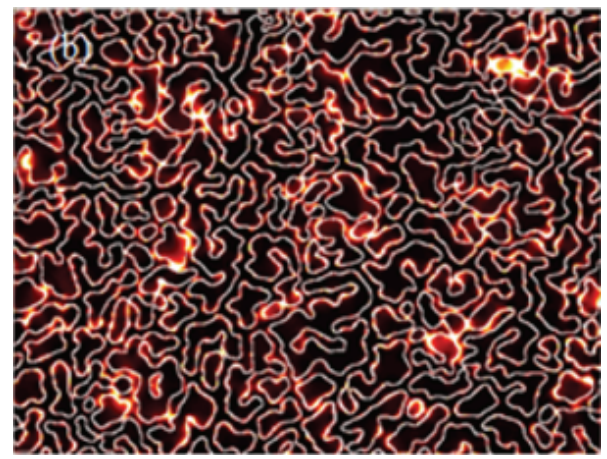

(b)

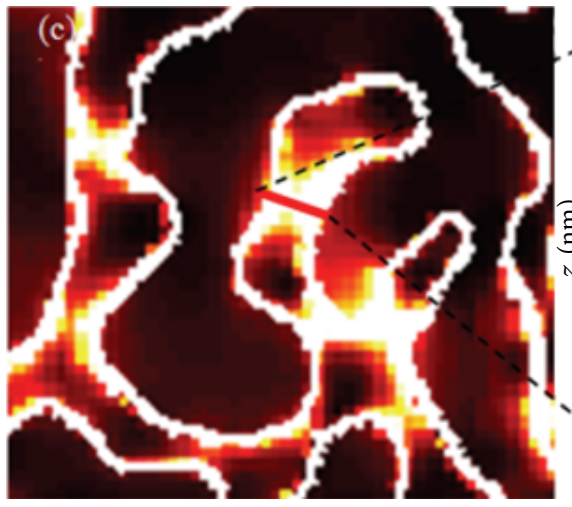

(c)

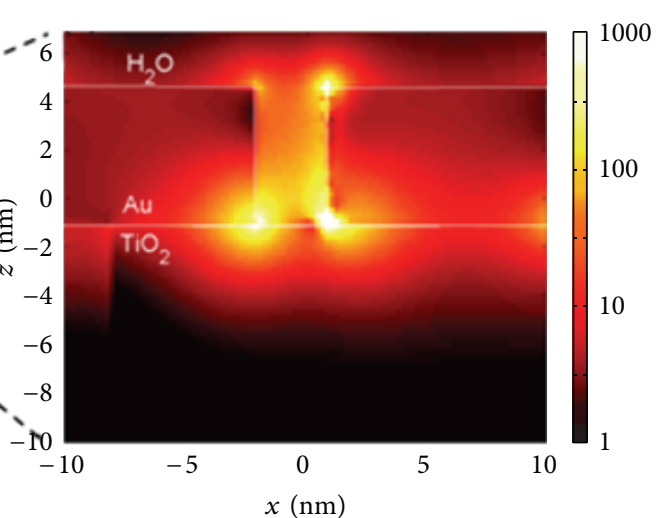

(d)

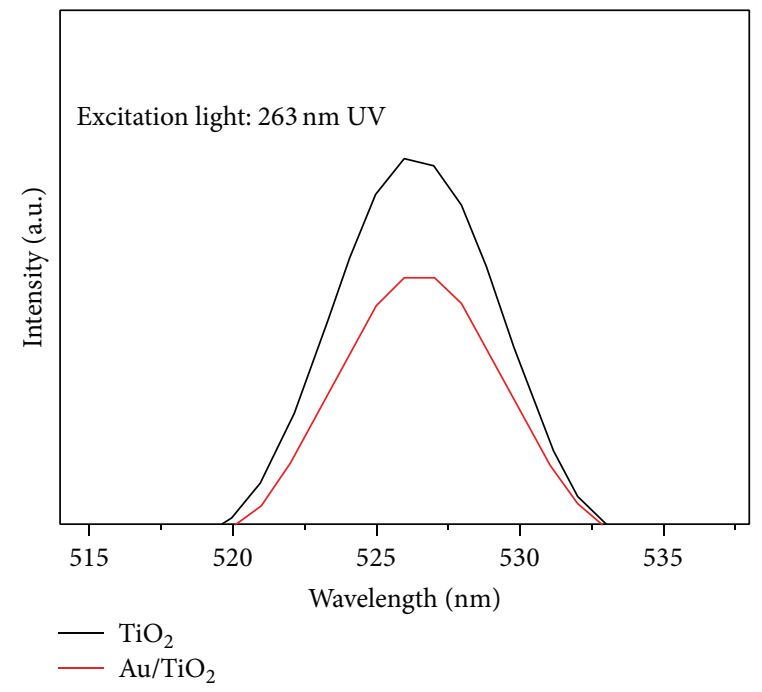

(e)

Figure 2: (a) SEM image of a $5 \mathrm{~nm}$ thick Au island film. (b-d) simulated electric field intensity observed from the top surface and cross section of the interface of $\mathrm{Au}-\mathrm{TiO}_{2}$ calculated using FDTD. (e) The Photoluminescence spectrum (PL) of $\mathrm{TiO}_{2}$ (black) and Au-TiO 2 (red) under excitation wavelength $(\lambda=263 \mathrm{~nm})$. 
remained rather low because the samples had a considerably lower surface area compared with current state-of-the-art Gratzel cells. The absolute efficiency can be improved beyond this proof-of-principle study by using host materials with a large surface area, such as $\mathrm{TiO}_{2}$ nanotubes, or nanowires to increase photon absorption sites.

To develop a comprehensive understanding of the plasmon-induced electric fields, we conducted FDTD simulations of the plasmon-induced electric distribution of the island-like Au film. Figures 2(b)-2(d) show the electromagnetic response of the Au island film, calculated using the FDTD method. We used the scanning electron microscope (SEM) image shown in Figure 2(a) to define the spatial extent of the $\mathrm{Au}$ islands in the simulation. Local hot spots were observed between nearly touching Au nanoparticles. Figure 2(d) shows a cross-sectional plot of the electric field distribution of one of these hot spot regions in the $z$-dimension. In this hot spot region, the electric field intensity at the $\mathrm{TiO}_{2}$ surface reached 1000 times that of the incident electric field intensity, suggesting that the photon absorption (and hence electron-hole pairs generation) rate was 1000 times higher than that of the incident electromagnetic radiation.

We calculated the enhancement factor on the basis of the results of the FDTD simulation. Because the photon absorption rate is proportional to the electric field squared $\left(|E|^{2}\right)$, we integrated $|E|^{2}$ over the whole film and divided it by the integral of the incident electromagnetic field squared $\left(\left|E_{0}\right|^{2}\right)$ as follows:

$$
\mathrm{EF}=\frac{\int_{-10 \mathrm{~nm}}^{0} d z \int d x d y|E|^{2}}{\int_{-10 \mathrm{~nm}}^{0} d z \int d x d y\left|E_{0}\right|^{2}} .
$$

In the $z$-dimension, we integrated only $|E|^{2}$ from the $\mathrm{TiO}_{2}$ surface $(z=0)$ with that from one exciton diffusion length below the surface $(z=-10 \mathrm{~nm})$. The value for the $\mathrm{EF}$ when $|E|^{2}$ was integrated over the entire simulation area $(400 \times 300 \mathrm{~nm})$ is $12 \mathrm{X}$. This EF value is higher than that observed in our experiment, most likely because of activity-absorbing N719 dye molecules inside the pores of the ATO structure, which are distant from the plasmonic $\mathrm{Au}$ film on the top surface of the ATO. In addition, this plasmon-enhanced absorption process competes with the recombination process because of the presence of metal nanoparticles as a recombination center, which was not considered in this FDTD simulation. However, this value is for a random distribution of $\mathrm{Au}$ islands that are not optimized geometrically. If we instead integrated $|E|^{2}$ over the area of only one hot spot, as shown in Figure 2(c), an EF of 190X would be yielded. The investigation of the charge transfer of photogenerated electron-hole pairs can be achieved using the photoluminescence (PL) emission spectrum, the signal of which indicates the recombination of free charge carriers. Figure 2(e) shows the PL spectra of different samples at an excitation wavelength of $263 \mathrm{~nm}(4.71 \mathrm{eV})$. According to the PL results, the intensity of emission peaks at approximately $525 \mathrm{~nm}$ decreased with the existence of Au NPs, and the weaker emission signal occurred in the Au/dye-loaded $\mathrm{TiO}_{2}$ sample. These results suggested that the recombination of

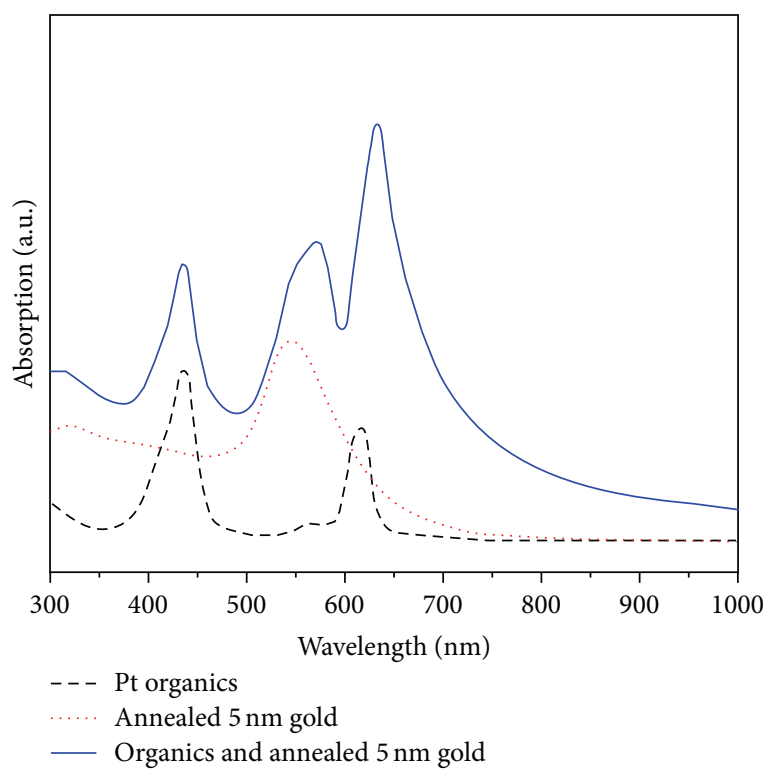

FIGURE 3: Absorption spectra of phosphorescence dye (black), $5 \mathrm{~nm}$ gold (red), and dye with $5 \mathrm{~nm}$ gold underneath (blue).

charge carriers was significantly reduced when Au NPs and dye-loaded $\mathrm{TiO}_{2}$ were integrated.

Finally, photoluminescence spectroscopy is carried out in order to rule out the noncharge transfer mechanism of plasmonic energy. Forster transfer (i.e., radiative energy transfer) depends on the interaction of the resonant dipoles between plasmonic NPs and dye molecules. This noncharge transfer pathway can be examined by taking photoluminescence spectra of plasmonic nanoparticles with phosphorescent dye. It is important to choose the proper phosphorescent dye, which is energetically allowed to absorb the plasmon resonant energy from metal nanoparticles. Here, we performed photoexcitation measurements on samples made of sol-gel $\mathrm{TiO}_{2}$, rather than ATO, loaded with the phosphorescent dye and platinum tetra (1,3-di-tert-butylphenyl) tetrabenzoporphyrin (Pt tbu (TPBP)) both with and without $5 \mathrm{~nm}$ gold films. The purpose of using phosphorescence dye (TPBP) is to create a scenario of nonoverlap absorption spectrum of the phosphorescence dye and plasmonic resonant energy of gold, as shown in the UV-Vis absorption spectra in Figure 3. This nonoverlap of absorption enables us to investigate whether or not Forster energy transfer occurs between the plasmons in the metal NPs and the excitons in the phosphorescent dye. Figure 4 shows the phosphorescent emission of the TPBP dye at $760 \mathrm{~nm}$ as a function of the incident of scanning wavelengths with/without gold NPs. However, there is no pronounced peak observed at the plasmon resonant wavelength of $532 \mathrm{~nm}$ in Figure 4(b), which is the corresponding plasmon resonant energy of the $5 \mathrm{~nm}$ gold film. The absence of a peak at $532 \mathrm{~nm}$ in the excitation spectrum indicates that most of plasmon energy is not transferred to the phosphorescent dye for reradiation through the Forster resonance energy transfer mechanism. These results indicate that the improvement of cell performance originates from another path, which we 


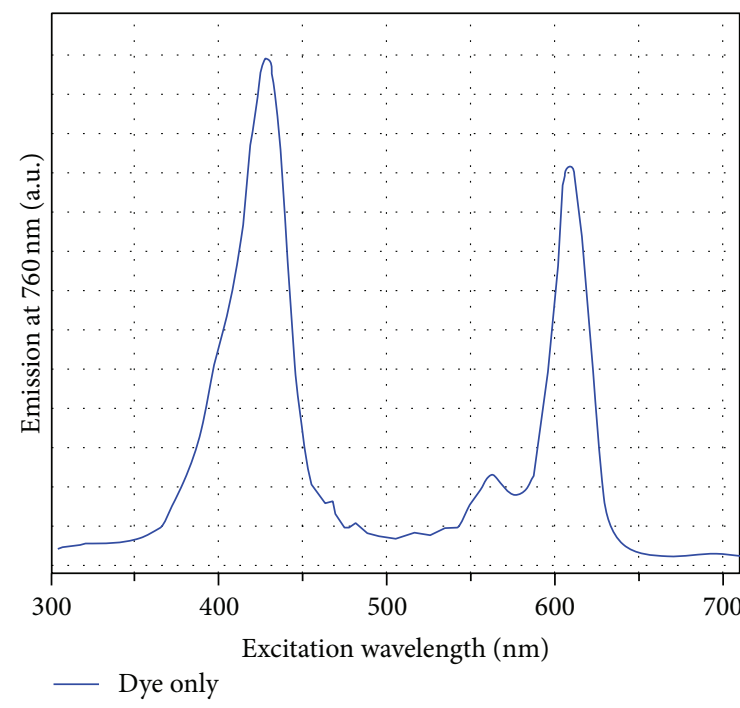

(a)

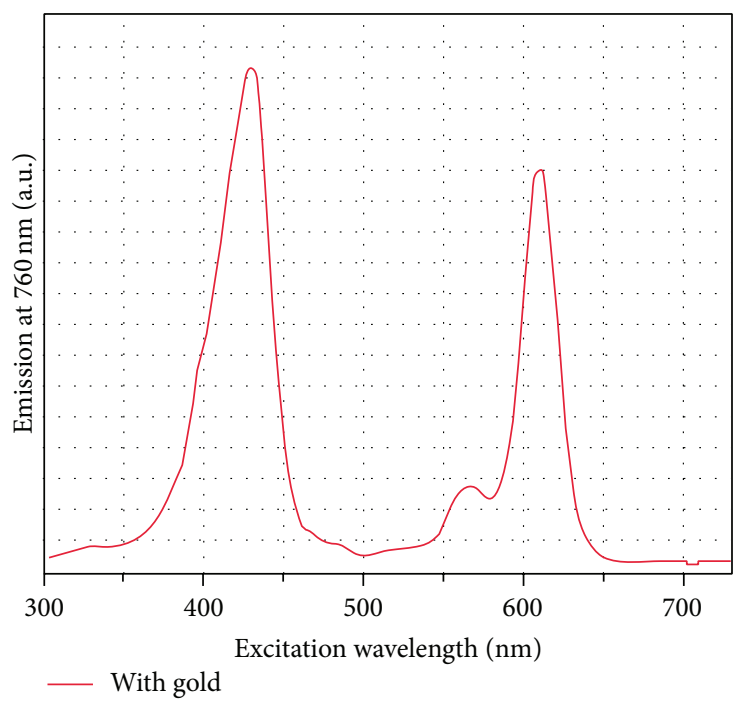

(b)

Figure 4: Emission spectra of (a) TPBP dye only and (b) TPBP dye with $5 \mathrm{~nm}$ gold film.

believe is due to the plasmon-induced electric field surrounding the plasmonic NPs.

In conclusion, we have successfully demonstrated plasmonic enhancement of dye sensitized solar cells with up to $45 \%$ improvement in the cell power conversion efficiency by simply integrating a layer of island-like plasmonic gold nanoparticles with an $\mathrm{N} 719 / \mathrm{TiO}_{2}$ DSSC. FDTD simulations are carried out in order to investigate the distribution of the plasmon-induced electric fields in the $5 \mathrm{~nm}$ island-like gold film. Furthermore, we believe the enhancement obtained in the dye sensitized cell is attributed to the plasmoninduced electric fields, which strongly increase the exciton generation rate. Photoluminescence spectroscopy rules out the mechanism of plasmon energy transfer through a Forster resonance energy transfer path.

\section{Conflict of Interests}

The authors state that there is no conflict of interests related to this paper.

\section{References}

[1] B. O'Regan and M. Graetzel, "A Low-cost, high-efficiency solarcell based on dye-sensitized colloidal $\mathrm{TiO}_{2}$ films," Nature, vol. 353, no. 6346, pp. 737-740, 1991.

[2] M. K. Nazeeruddin, F. de Angelis, S. Fantacci et al., "Combined experimental and DFT-TDDFT computational study of photoelectrochemical cell ruthenium sensitizers," Journal of the American Chemical Society, vol. 127, no. 48, pp. 16835-16847, 2005.

[3] M. Grätzel, "Photoelectrochemical cells," Nature, vol. 414, no. 6861, pp. 338-344, 2001.

[4] J. Nelson, The Physics of Solar Cells, Imperial College Press, London, UK, 2003.
[5] K. Hara, T. Sato, R. Katoh et al., "Molecular design of coumarin dyes for efficient dye-sensitized solar cells," The Journal of Physical Chemistry B, vol. 107, no. 2, pp. 597-606, 2003.

[6] S. M. Zakeeruddin, M. K. Nazeeruddin, P. Pechy et al., "Molecular engineering of photosensitizers for nanocrystalline solar cells: synthesis and characterization of Ru dyes based on phosphonated terpyridines," Inorganic Chemistry, vol. 36, no. 25, pp. 5937-5946, 1997.

[7] R. J. Ellingson, M. C. Beard, J. C. Johnson et al., "Highly efficient multiple exciton generation in colloidal $\mathrm{PbSe}$ and $\mathrm{PbS}$ quantum dots," Nano Letters, vol. 5, no. 5, pp. 865-871, 2005.

[8] R. D. Schaller, M. Sykora, J. M. Pietryga, and V. I. Klimov, "Seven excitons at a cost of one: redefining the limits for conversion efficiency of photons into charge carriers," Nano Letters, vol. 6, no. 3, pp. 424-429, 2006.

[9] M. Moskovits, "Surface-enhanced spectroscopy," Reviews of Modern Physics, vol. 57, no. 3, pp. 783-826, 1985.

[10] H. H. Wei, H. I-Kai, A. Bushmaker, R. Kumar, J. Theiss, and S. B. Cronin, "Laser directed growth of Carbon-Based nanostructures by plasmon resonant chemical vapor deposition," Nano Letters, vol. 8, no. 10, pp. 3278-3282, 2008.

[11] W. H. Hung, M. Aykol, D. Valley, W. Hou, and S. B. Cronin, "Plasmon resonant enhancement of carbon monoxide catalysis," Nano Letters, vol. 10, no. 4, pp. 1314-1318, 2010.

[12] X.-Y. Zhu, Q. Yang, and M. Muntwiler, "Charge-transfer excitons at organic semiconductor surfaces and interfaces," Accounts of Chemical Research, vol. 42, no. 11, pp. 1779-1787, 2009.

[13] H. A. Atwater and A. Polman, "Plasmonics for improved photovoltaic devices," Nature Materials, vol. 9, no. 3, pp. 205$213,2010$.

[14] J. H. Lee, J. H. Park, J. S. Kim, D. Y. Lee, and K. Cho, "High efficiency polymer solar cells with wet deposited plasmonic gold nanodots," Organic Electronics, vol. 10, no. 3, pp. 416-420, 2009.

[15] B. P. Rand, P. Peumans, and S. R. Forrest, "Long-range absorption enhancement in organic tandem thin-film solar cells containing silver nanoclusters," Journal of Applied Physics, vol. 96, no. 12, pp. 7519-7526, 2004. 
[16] M. D. Brown, T. Suteewong, R. S. S. Kumar et al., "Plasmonic dye-sensitized solar cells using core-shell metal-insulator nanoparticles," Nano Letters, vol. 11, no. 2, pp. 438-445, 2011.

[17] A. P. Kulkarni, K. M. Noone, K. Munechika, S. R. Guyer, and D. S. Ginger, "Plasmon-enhanced charge carrier generation in organic photovoltaic films using silver nanoprisms," Nano Letters, vol. 10, no. 4, pp. 1501-1505, 2010.

[18] D. Duche, P. Torchio, L. Escoubas et al., "Improving light absorption in organic solar cells by plasmonic contribution," Solar Energy Materials and Solar Cells, vol. 93, no. 8, pp. 13771382, 2009.

[19] A. J. Morfa, K. L. Rowlen, T. H. Reilly III, M. J. Romero, and J. van de Lagemaat, "Erratum: plasmon-enhanced solar energy conversion in organic bulk heterojunction photovoltaics [Appl. Phys. Lett. 92, 013504 (2008)]," Applied Physics Letters, vol. 92, no. 13, Article ID 139901, 2008.

[20] C. A. Grimes, "Synthesis and application of highly ordered arrays of $\mathrm{TiO}_{2}$ nanotubes," Journal of Materials Chemistry, vol. 17, no. 15, pp. 1451-1457, 2007.

[21] Z. Liu, W. Hou, P. Pavaskar, M. Aykol, and S. B. Cronin, "Plasmon resonant enhancement of photocatalytic water splitting under visible illumination," Nano Letters, vol. 11, no. 3, pp. 11111116, 2011.

[22] D. C. Fu, X. L. Zhang, R. L. Barber, and U. Bach, "Dye-sensitized back-contact solar cells," Advanced Materials, vol. 22, no. 38, pp. 4270-4274, 2010. 

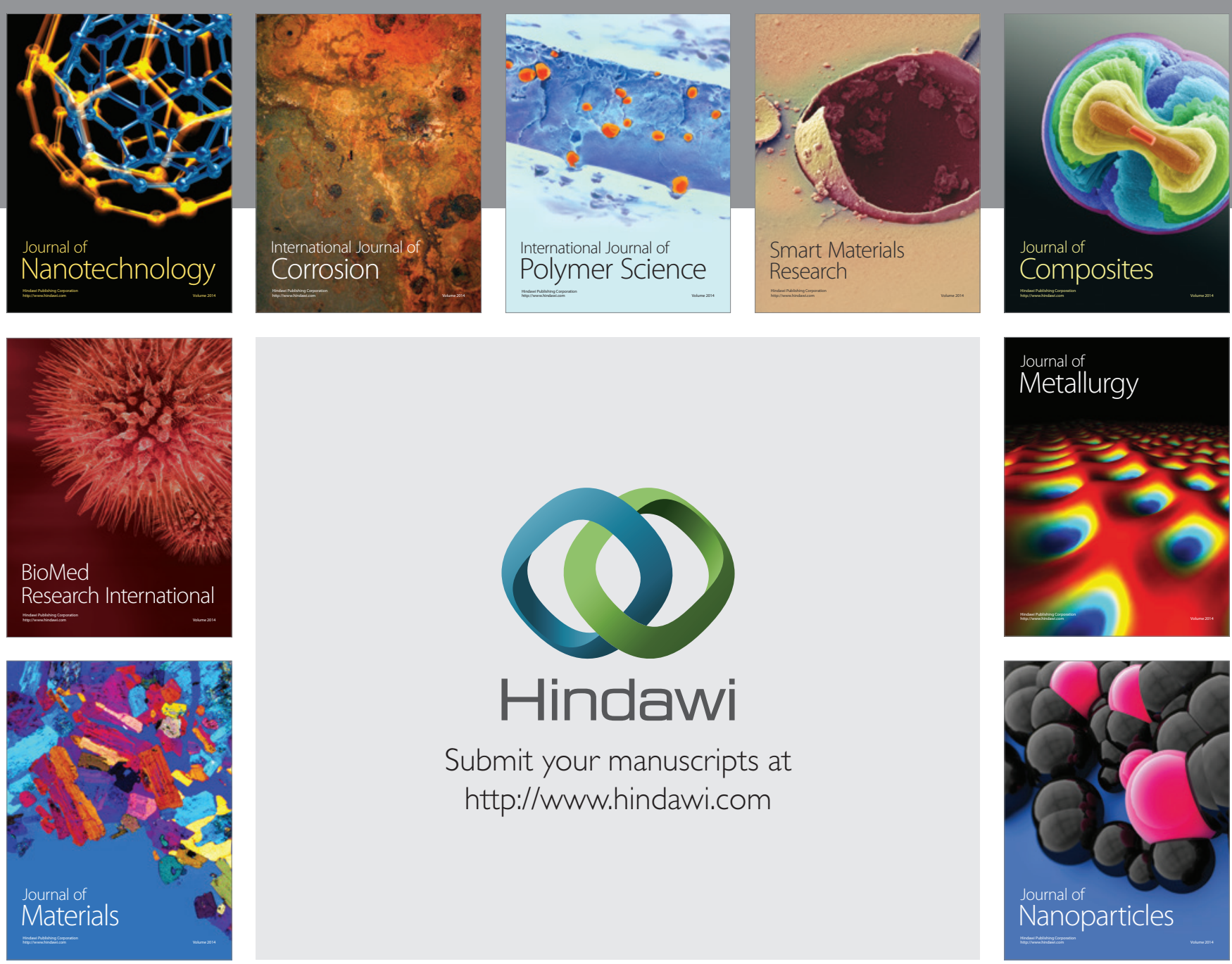

Submit your manuscripts at http://www.hindawi.com
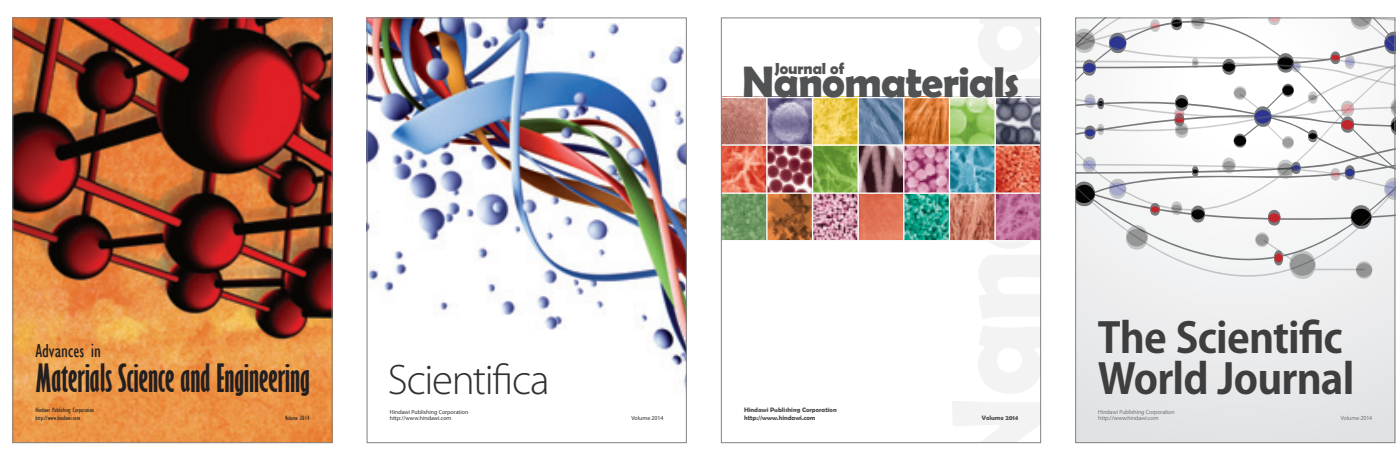

\section{The Scientific World Journal}
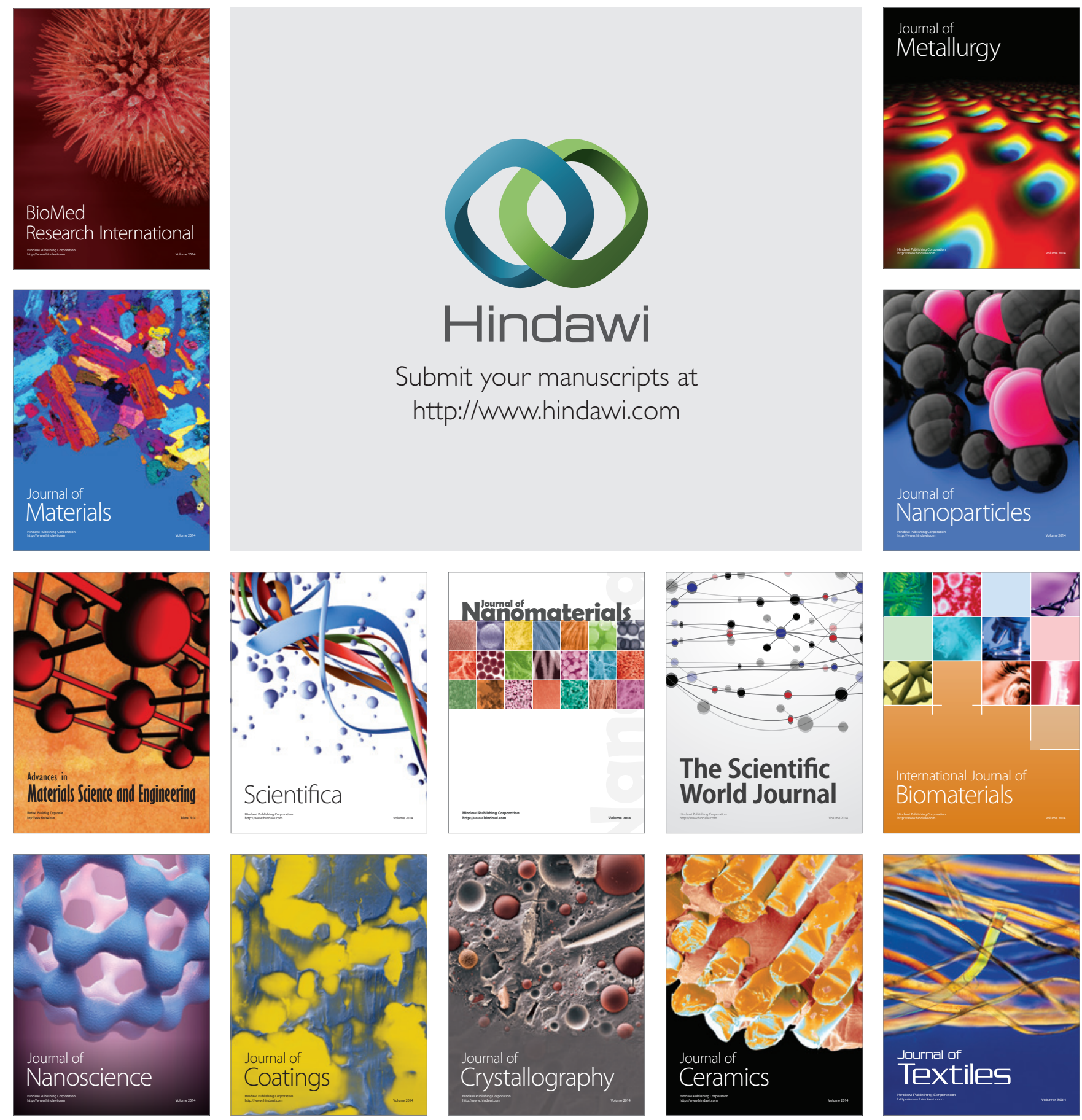